\title{
CITRULINA SÉRICA COMO MARCADOR DE REJEIÇÃO CELULAR AGUDA EM TRANSPLANTE INTESTINAL EM RATOS
}

\author{
Serum citrulline as a marker for rejection in intestinal transplant in rats
}

Andre I. David ${ }^{1,3}$, Lara Sekiguchi',3, Sergio Santiago', Carlos Gandia', Wervinston de Faria', Gary Kleiner², Andreas G. Tzakis ${ }^{1}$

\begin{abstract}
RESUMO
Introdução: O objetivo deste estudo foi relacionar os níveis de citrulina sérica à rejeição celular aguda após transplante intestinal, avaliando a citrulina como método laboratorial menos invasivo e de menor custo que a biópsia endoscópica para diagnosticar a mais importante complicação após transplante intestinal. Métodos: Estudo aprovado pelo Comitê de Ética em Pesquisa com Animais e realizado em caráter experimental no Batchelor Research Institute da Universidade de Miami, no período de agosto a dezembro de 2004. Foram realizados cinco transplantes heterotópicos de intestino, com duas estomias e vascularização da artéria mesentérica superior na aorta e drenagem venosa do mesentério na veia cava. Amostras de sangue foram colhidas no $3^{\circ}, 5^{\circ}$ e $7^{\circ}$ dias pré- e pós-operatórios. Resultados: Os níveis de citrulina sérica variaram de 78 a $99 \mu \mathrm{mol} / \mathrm{L}$ no pré-transplante, de 44 a $54 \mu \mathrm{mol} / \mathrm{L}$ no pós-transplante 3 , de 62 a $73 \mu \mathrm{mol} / \mathrm{L}$ no pós-transplante 5 e de 36 a $60 \mu \mathrm{mol} / \mathrm{L}$ no pós-transplante 7. Os níveis médios de citrulina sérica nos pós-transplante 3,5 e 7 foram significativamente menores comparados ao correspondente no pré-transplante. Conclusão: Os níveis séricos diminuíram durante a rejeição celular aguda, o que pode indicar a citrulina como marcadora precoce de episódios de rejeição celular aguda no transplante intestinal.
\end{abstract}

Descritores: Citrulina, Rejeição, Transplante, Intestinos, Ratos.

\section{Instituição:}

${ }^{1}$ Surgery Department at University of Miami School of Medicine, Miami, FL

2 Pediatric Department at University of Miami School of Medicine, Miami, FL

${ }^{3}$ Departamento de Cirurgia da Faculdade de Medicina Santa Casa de São Paulo, São Paulo, Brasil

\section{Correspondência:}

André I. David

Rua Cesário Motta Jr., 112 - Vila Buarque

CEP 01221-020 - São Paulo - SP, Brasil

Tel.: 5511 2176-7699 / 3666-7307

Email: drandredavid@terra.com.br

Recebido em: 20.12 .2006

\section{INTRODUÇÃO}

O transplante intestinal (TI) tornou-se o tratamento de escolha para doentes com síndrome do intestino curto ou com complicações graves da nutrição parenteral prolongada. A melhora na sobrevivência após o TI deve-se ao aprimoramento das medicações imunossupressoras, aperfeiçoamento técnico das equipes e dos métodos de controle da rejeição aguda. ${ }^{1-3}$

As indicações de TI também incluem outras quatro situações: elevado risco de morte decorrente de falência intestinal crônica (pseudo-obstrução intestinal, isquemia mesentérica, tumor desmóide, doença de Crohn e doença de Hirschsprung), acessos venosos insuficientes para nutrição parenteral doméstica e tumores abdominais localmente invasivos. ${ }^{1,4,5}$

Em contraste com o transplante de rim e de fígado, nos quais a creatinina sérica e enzimas hepáticas são utilizadas respectivamente como indicadores de disfunções, o transplante intestinal ainda não dispõe de um marcador biológico de lesão tecidual plenamente estabelecido.6 É importante salientar a relevância de tal descoberta no diagnóstico da principal complicação do transplante intestinal: a rejeição do enxerto. Isso porque, atualmente, a endoscopia com biópsia é o único exame utilizado no diagnóstico de rejeição no TI. Trata-se, porém, de um procedimento invasivo e de alto custo. 
A citrulina sérica (CS), um aminoácido não-protéico, foi sugerida como marcadora de lesão intestinal em receptores de transplante de intestino.7 Esse composto orgânico é produzido quase exclusivamente por enterócitos a partir da conversão da glutamina, sendo em seguida liberado na circulação portal e metabolizado em arginina nos rins. ${ }^{8}$

A análise clínica do período pós-transplante nos receptores de transplante intestinal mostrou redução dos níveis de CS durante episódios de rejeição e infecção em nossos doentes ${ }^{7,9}$.

Foi desenvolvido um modelo de transplante intestinal em ratos por Monchik e Russell, em 1971, e aprimorado por Soins \& Friend em 1996, possibilitando aumento do número de cirurgias bemsucedidas e redução do período operatório na experimentação10.

\section{OBJETIVO}

Análise da citrulina sérica como marcador de rejeição celular aguda em transplante intestinal em rato.

\section{MATERIAL E MÉTODO}

Estudo realizado em caráter experimental no Batchelor Research Institute da Universidade de Miami, no período de agosto a dezembro de 2004, aprovado pelo Comitê de Ética em Pesquisa com Animais. Foram realizados cinco transplantes heterotópicos de intestino em ratos jovens com peso entre 180 a 200 gramas. Os animais eram provenientes do biotério, com controle de temperatura, higiene e ritmo circadiano. Utilizaram-se ratos de espécies diferentes: doadores DA e receptores Lewis. A análise estatística foi realizada com o teste " $t$ " de Student para a análise das médias.

O procedimento do transplante foi realizado conforme descrição prévia de Santiago e col. (1991), heterotópico e com duas estomias com vascularização da artéria mesentérica superior na aorta e drenagem venosa do mesentério na veia cava. ${ }^{11}$

Foram colhidas amostras de sangue para dosagem de citrulina sérica no pré-operatório e nos dias 3, 5 e 7 após o transplante. No sétimo dia, o animal foi sacrificado e foram realizadas biópsias do intestino transplantado (figura 1).

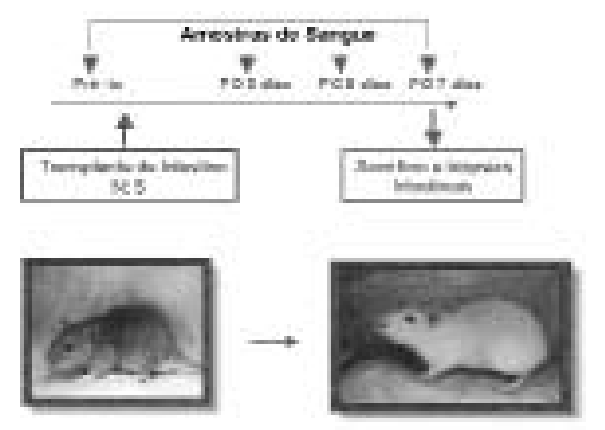

Figura 1. Diagrama do método de coleta das amostras de sangue.

\section{RESULTADOS}

Os valores da CS variaram de 78 a $99 \mu \mathrm{mol} / \mathrm{L}$ no pré-TI, de 44 a $54 \mu \mathrm{mol} / \mathrm{L}$ no pós-operatório 3 (PO3), de 62 a $73 \mu \mathrm{mol} / \mathrm{L}$ no pós- operatório 5 (PO5) e de 36 a $60 \mu \mathrm{mol} / \mathrm{L}$ no pós-operatório 7 (PO7) (figura 2). $\mathrm{O}$ valor médio de $\mathrm{CS}$ encontrado no pré-operatório foi de $97 \pm 13 \mu \mathrm{mol} / \mathrm{L}$. Nos dias PO3, PO5 e PO7 foram encontrados valores de $52 \pm 5,67 \pm-4$ e $46 \pm 10 \mu \mathrm{mol} / \mathrm{L}$, respectivamente (figura 3 ).

O nível médio da CS foi significativamente menor nos 3, 5 e 7 o dias pós-operatórios, comparados ao do período pré-operatório $(p<0,0001)$ (tabela 1). A rejeição do enxerto foi confirmada no PO7 e coincide com a menor média de CS em comparação com o valor pré-TI $(\mathrm{p}<0,0001)$ (tabela 1$)$.

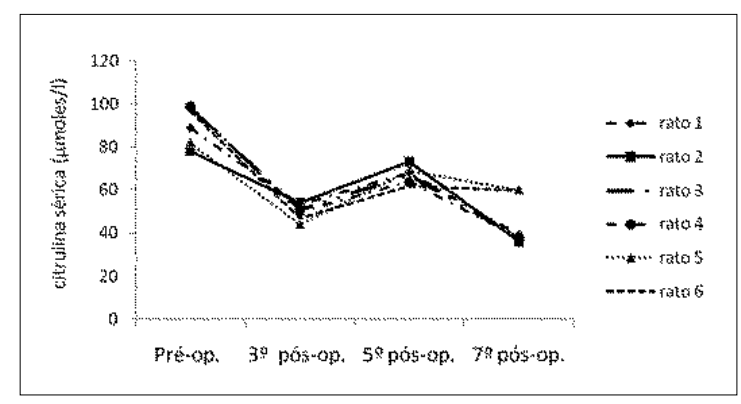

Figura 2: Níveis de citrulina sérica em rejeição de enxerto de intestino delgado (valores absolutos).

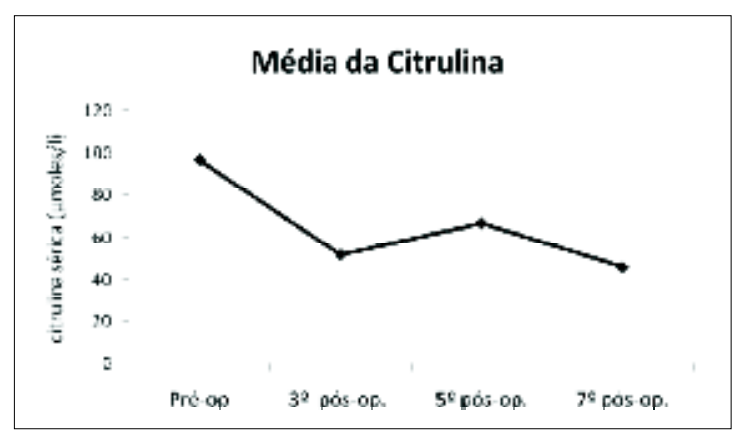

Figura 3: Média de concentração de citrulina sérica durante pré e pós-transplante intestinal heterotópico.

Tabela 1. Média de Concentração de Citrulina sérica durante pré e póstransplante intestinal heterotópico $(\mu \mathrm{mol} / \mathrm{L})$.

\begin{tabular}{ccccc}
\hline & Pré-Transplante & Pós-Transplante & & \\
\hline 3 dias & 5 dias & 7 dias & \\
Média \pm DP & $97 \pm 13^{a}$ & $52 \pm 5 \mathrm{~b}$ & $67 \pm 4 \mathrm{c}$ & $46 \pm 10 \mathrm{~d}$ \\
\hline
\end{tabular}

b: $P<0,001 V s$ a \& $d$

c: $P<0,001$ Vs $c$;

c: $P<0,0001$ Vs a \& $d$;

$d: P<0,001 \mathrm{Vs}$ a \& $\mathrm{c}$.

\section{DISCUSSÃO}

A literatura é escassa em informações referentes à dosagem de CS em ratos, especialmente após TI. Neste estudo, avaliamos o comportamento da CS diante da rejeição do enxerto. A CS foi estatisticamente menor nos episódios de rejeição celular aguda nos dias 5 e 7 pós-transplante, sendo mais importante no dia 7, quando a rejeição foi confirmada através da biópsia. 
Analisando a figura 3, na curva 1, a CS sofreu queda na média de $45 \mu \mathrm{mol} / \mathrm{L}$ devido à lesão de isquemia e reperfusão do enxerto. Na correlação clínica, a redução dos níveis de CS no período póstransplante decorreu de isquemia-reperfusão do enxerto intestinal. ${ }^{12} \mathrm{Na}$ curva 2, o aumento de $15 \mu \mathrm{mol} / \mathrm{L}$ de CS na média pode ser explicado pela recuperação da função dos enterócitos. Clinicamente, a média de normalização do nível de CS nos 21 doentes estudados foi de 79 dias após o TI7. Na curva 3 a diminuição importante de $21 \mu \mathrm{mol} / \mathrm{L}$ de CS pode ser justificada pela presença de lesão tecidual, decorrente do processo de rejeição. Correlacionando com a clínica, os doentes que apresentaram rejeição apresentaram níveis diminuídos de CS em relação ao nível normal. ${ }^{7} \mathrm{O}$ atraso da normalização dos níveis de CS no pós-operatório foi associado aos maiores graus de rejeição.7,12,13 O tempo estimado de recuperação do nível normal de CS variou entre 1 e 730 dias após o transplante de 21 doentes estudados. ${ }^{12}$

Estudos indicaram que o nível "normal" de CS varia com a idade, apresentando valores entre 3 e $55 \mu \mathrm{mol} / \mathrm{L}$ com uma média de 38 $\pm 8 \mu \mathrm{mol} / \mathrm{L}$ de amostras obtidas em doentes saudáveis.8,13-15 Por outro lado, Pappas e col., em 2004, mostraram que o nível normal da citrulina sérica foi maior ou igual a $30 \mu \mathrm{mol} / \mathrm{L}$.

Em receptores de transplante intestinal que não sofreram rejeição ou outras anormalidades histológicas, a média global de citrulina sérica $(\mathrm{nmol} / \mathrm{mL})$ foi de 34,0 $\pm 19,9$ (14,1-5,9). Analisando o período pósoperatório, tem-se que: a média foi de $22,2 \pm 13,2(9-35,4)$ entre o $6^{-}$ e o $30^{\circ}$ dias; $34,9 \pm 17,2(17,7-52,1)$ entre o $30^{\circ}$ e e o $60^{\circ}$ dias; $43,6 \pm 15,8$ $(27,8-59,4)$ entre os $60^{\circ}$ e $90^{\circ}$ dias $(p=0,001)$, tornando-se estável até o fim do primeiro ano. A citrulina plasmática foi menor em doentes com área de superfície corporal igual (ASC) ou inferior a $1 \mathrm{~m}^{2}$ quando comparados aos que tinham ASC igual ou superior a $1,1 \mathrm{~m} 2 .{ }^{16}$

\section{CONCLUSÃO}

O comportamento da Citrulina até PO3 mostrou um decréscimo seguido de discreto aumento, sem recuperação nos níveis normais pré-TI. Os níveis séricos diminuíram durante a rejeição celular aguda confirmada por biópsia.

\section{ABSTRACT}

Purpose: The objective of this study was to correlate the serum citrulline levels to the acute cellular rejection after intestinal transplant, therefore establishing a cheaper and less invasive method of intestinal transplant rejection diagnosis. Methods: The experimental study took place at the Batchelor Research Institute of the University of Miami in the period between August and December, 2004 duly approved by the Ethics Committee on Animal Research. Five intestinal transplants were performed in Lewis rats that received intestinal grafts from DA rats, as previously described by SANTIAGO et al. Blood samples were collected in the pre- and post-surgical period at days 3rd, 5th, and 7th. Results: Serum citrulline levels ranged from 78 to $99 \mu \mathrm{mol} / \mathrm{L}$ in pre-transplant period; from 44 to $54 \mu \mathrm{mol} / \mathrm{L}$ in post-transplant 3; from 62 to $73 \mu \mathrm{mol} / \mathrm{L}$ in post-transplant 5 , and from 36 to $60 \mu \mathrm{mol} / \mathrm{L}$ in post-transplant 7 . Mean serum citrulline levels in 3,5 , and 7 post-transplant days were significantly smaller compared to the pre-transplant level. Conclusion: Serum citrulline levels declined along the acute cellular rejection, and this may point citrulline as a marker for the early detection of acute rejection episodes.

Keywords: Citrulline, Rejection, Transplantation, Intestines, Rats.

\section{REFERÊNCIAS}

1. Goulet O JD, Lacaille F, Colomb V, Michel JL, Damotte D, Jouvet P, et al. Intestinal transplantation in children: preliminary experience in Paris. J Parenter Enteral Nutr. 1999;23(5):121-5.

2. Tzakis AG, Kato T LD, et al. 100 multivisceral transplants at a single center. Annals of Surgery. 2005;242:480-93.

3. Kato TA, Gennaro S, et al. Intestinal and multivisceral transplantation in children. Annals of Surgery. 2006;243(6):756-66.

4. Goulet O SF. Short bowel syndrome and intestinal transplantation in children. Curr Opin Clin Nutr Metab Care. 2006;9(3):304-13.

5. Pironi SG, Paganelli F, Merli C, Masetti M, Miglioli M, Pinna AD. Italian guidelines for intestinal transplantation: potential candidates among the adult patients managed by a medical referral center for chronic intestinal failure. Transplant Proc. 2004;36(3):659-61

6. Yu TS, Moon JI, et al. Utilization of dried blood spot citrulline level as a noninvasive method for monitoring graft function following intestinal transplantation. Transplantation. 2005;80(12):1729-33.

7. Pappas PA, Gaynor JJ, et al. An analysis of the association between serum citrulline and acute rejection among 26 recipients of intestinal transplant. American Journal of Transplantation. 2004;4(7):1124-32.
8. Curis E Nicolis I MC, et al. Almost all about citrulline in mammals. Amino Acids. 2005;29(3):177-205.

9. Pappas PA, Saudubray JM, Tzakis AG, Rabier D, Carreno MR, Gomez-Marin O, et al. Serum citrulline as a marker of acute cellular rejection for intestinal transplantation. Transplantation Proceedings. 2002;34(3):915-7.

10. Soin AS. A modification to improve technical success rate of small bowel transplantation in rats. Transplant Proc.1996;28(5):2722.

11. Santiago FM, Azuma T, Okada A. Effect of donor pretreatment with FK 506 uponsmall intestine allotransplantation in rats. Transplant Proc. 1991;23(6):3243-5.

12. Pappas PA, Saudubray JM, Gaynor JJ, Carreno MR, Huijing F, Kleiner G, et al. Trends in serum citrulline and acute rejection among recipients of small bowel transplants. Transplant Proc. 2004;36(2):345-7.

13. Gondolesi GS, Raymond K, et al. The value of plasma citrulline to predict mucosal injury in intestinal allografts. American Journal of Transplantation. 2006;6(11):2786-90.

14. Lepage MN, Dallaire L, et al. Age-specific distribution of plasma amino acid concentrations in a healthy pediatric population. Clinical Chemistry. 1997;43(12):2397-402.

15. LA C. Plasma amino acid levels with a note on membrane transport: Characteristics, regulation, and metabolic significance. Nutrition. 2002:18(9):761-6

16. Gondolesi GE KS, Sansaricq C, et al. Defining normal plasma citrulline in intestinal transplant recipients. American Journal of Transplantation. 2004;4(3):414-8. 